\title{
MEMÓRIA, CONSCIÊNCIA, SELF: CONTRIBUIÇÕES PARA A PESQUISA (AUTO)BIOGRÁFICA COM
}

\section{CRIANÇAS}

ANDRÉ AUGUSTO DINIZ LIRA

https://orcid.org/0000-0001-9398-507X

Universidade Federal de Campina Grande

RENATA CARLOS DE OLIVEIRA GONÇALVES

https:/ /orcid.org/0000-0001-8208-3775

Universidade Federal de Campina Grande

RESUMO Este artigo analisa estudos sobre o desenvolvimento da memória, da consciência e do self, privilegiando abordagens da psicologia do desenvolvimento e da neurociência, no intuito de dialogar com a pesquisa (auto)biográfica com crianças em educação. Na psicologia do desenvolvimento, revisitamos a tradição de estudos de Vigotski, destacando a proposição do drama como uma categoria fundamental para as funções psicológicas superiores, e de Jerome Bruner retomamos a discussão sobre narrativas e construção do self. Consideramos as obras de Alison Gopnik na perspectiva da teoria da mente e de Katherine Nelson na discussão sobre o self em desenvolvimento, a memória autobiográfica, a narrativa autobiográfica e a consciência autobiográfica, como diferentes instâncias de complexidade e interdependência. Na Neurociência, focamos os estudos sobre a consciência humana e suas relações com o self em Oliver Sacks e em António Damásio. Concluímos ressaltando a contribuição dos estudos nas perspectivas desenvolvimentais para a ampliação de um olhar integrado sobre a memória, a consciência e o self na pesquisa (auto) biográfica, sobretudo com crianças.

Palavras-chave: Self. Consciência. Memória autobiográfica. Desenvolvimento. Pesquisas com crianças.

ABSTRACT MEMORY, CONSCIOUSNESS, SELF: CONTRIBUTIONS TO (SELF)BIOGRAPHIC RESEARCH WITH CHILDREN

This article analyzes studies on the development of memory, consciousness and self, focusing on developmental psychology and neuroscience approaches, in order to dialogue with (auto) biographical 
research with children in education. In developmental psychology, we revisit the tradition of studies by Vigotski, highlighting the proposition of drama as a fundamental category for higher psychological functions, and by Jerome Bruner we return to the discussion of narratives and construction of the self. We consider the works of Alison Gopnik from the perspective of the theory of mind and Katherine Nelson in the discussion of the developing self, autobiographical memory, autobiographical narrative and autobiographical consciousness, as different instances of complexity and interdependence. In Neuroscience, we focus on studies on human consciousness and its relations with the self in Oliver Sacks and António Damásio. We conclude by emphasizing the contribution of studies in developmental perspectives to the expansion of an integrated look at memory, consciousness and the self in (auto) biographical research, especially with children.

Keywords: Self. Consciousness. Autobiographical memory. Development. Research with children.

\section{RESUMEN MEMORIA, CONCIENCIA, SELF: CONTRIBUCIONES A LA INVESTIGACIÓN (AUTO)BIOGRÁFICA CON NIÑOS}

Este artículo analiza estudios sobre el desarrollo de la memoria, la conciencia y el yo, centrándose en enfoques de la psicología del desarrollo y la neurociencia, para dialogar con la investigación (auto) biográfica con niños en la educación. En psicología del desarrollo, revisamos la tradición de estudios de Vigotski, destacando la proposición del drama como una categoría fundamental para las funciones psicológicas superiores, y por Jerome Bruner volvemos a la discusión de las narrativas y la construcción del yo. Consideramos las obras de Alison Gopnik desde la perspectiva de la teoría de la mente y de Katherine Nelson en la discusión del yo en desarrollo, la memoria autobiográfica, la narrativa autobiográfica y la conciencia autobiográfica, como diferentes instancias de complejidad e interdependencia. En Neurociencia nos centramos en los estudios sobre la conciencia humana y sus relaciones con el yo en Oliver Sacks y António Damásio. Concluimos destacando la contribución de los estudios en perspectivas de desarrollo a la expansión de una mirada integrada a la memoria, la conciencia y el yo en la investigación (auto) biográfica, especialmente con niños.

Palabras clave: Self. Conciencia. Memoria autobiográfica. Desarrollo. Investigación con niños. 


\section{Introdução}

Nas últimas décadas, as pesquisas sobre o desenvolvimento infantil têm revisitado conhecimentos por muito tempo estabelecidos, sobretudo, no campo da inteligência, inclusive de tradição piagetiana e vigotskiana (HOUDÉ, MELJAC, 2000; GOLPNIK, 2010). Algumas pesquisas têm se desenvolvido no terreno da teoria da mente, utilizando metodologias que se pautam mais na observação do fazer infantil, pondo em relevo metáforas da criança como cientista, filósofa, matemática, física (GOPNIK, 2009). Algumas, utilizam-se de uma abordagem mais integrativa, articulando várias estratégias metodológicas (NELSON, 2006). Outras, pautam-se na neurociência, destacando-se observações da clínica neurológica e as pesquisas com neuroimagens (DAMÁSIO, 1996, 1999; SACKS, 2017). O estudo do desenvolvimento da memória, do self e da consciência em bebês e com crianças pequenas, nesse quadro, é ainda um desafio, aliás, até mesmo com adultos. Nesse sentido, alguns títulos de artigos e livros são provocativos como, por exemplo, A mente desconhecida: por que a ciência não consegue replicar, medicar e explicar o cérebro humano (HORGAN, 2002), e "O que os bebês sabem e os adultos desconhecem" (GOPNIK, 2010).

Os trabalhos sobre as relações entre a memória, a consciência e o self, desde a década de 1990, têm sido progressivos. Apesar do avanço no debate, ainda é possivel encontrar abordagens mais centradas em um dos aspectos do seu funcionamento de modo isolado. Nesses trabalhos, a discussão de memória autobiográfica está ausente, ainda que se procure em alguns casos fazer relações com a educação (FIORI, 2006; MADRUGA, MARTINEZ, CHAVES, 2014).

Uma das abordagens do estudo da memória que mais se desenvolveu foi tecida no campo das ciências sociais, da história e da psico- logia social, enfocando as identidades e suas relações com o poder (eg. SELIGMAN-SILVA, 2003; SÁ, 2005; LIRA, 2004). Esses estudos põem em relevo crianças concretas, que vivem, sobrevivem, convivem com o mundo adulto e os percalços que a vida thes impõe. Por decorrência, algumas dessas crianças são silenciadas, outras são silenciosas. Algumas cheias de vitalidade e fantasia, outras na marginalidade servil, entrecortadas por vicissitudes históricas e por diferentes posicionamentos no mundo social (DEMARTINI, 2009; MARTINS, 2014). Nos estudos sobre o self, há também uma série de textos que se pautam numa visão mais social. Cientistas sociais da envergadura de Giddens, Bauman e Raud produziram textos sociológicos nesse direcionamento (GIDDENS, 2002; BAUMAN, RAUD, 2018). Nikolas Rose (2011)' propôs um trabalho histórico e epistemológico na linha da subjetividade foucaultiana sobre o self. Contudo, tradicionalmente o termo é mais utilizado e as pesquisas sobre o self são mais desenvolvidas na área de psicologia.

Este artigo é fruto de uma pesquisa de revisão teórica que enfoca as relações entre o desenvolvimento da memória, da consciência e do self no intuito de buscar contribuições para

1 É importante destacar que nem sempre o leitor de língua portuguesa apreenderá de imediato que se tratam de livros sobre o self, uma vez que tradutores/editores têm recorrido a artifícios que terminam por não visibilizar essa relação diretamente. 0 livro de Bauman tem por título original Modernity and self-identity: self and Society in the late modern age, mas foi traduzido por Modernidade e identidade, perdendo-se assim a vinculação com o self. O livro de Bauman e Raud (2018), Practices of Selfhood, foi por sua vez traduzido por A individualidade numa época de incertezas. Apesar de não ter o self em destaque no título, os capítulos mostram claramente essa relação. Por fim e de um modo contrário ao ocultamento, o título da obra de Rose (2011) - Inventing our selves: Psychology, Power, and Selfhood -, foi traduzido por Inventando nossos selfs: psicologia, poder e subjetividade. 0 artificio é o de não se adotar o plural selves na tradução e acrescentar erroneamente um $\mathrm{s}$ em self para atrair a atenção do leitor de língua portuguesa, o que vale um nota explicativa do tradutor no início do livro. 
a pesquisa (auto)biográfica com crianças. Privilegiamos, no corpus investigado, pesquisas sobre o desenvolvimento humano em psicologia e a discussão conduzida pela neurociência. Nessa perspectiva, revisitamos primeiramente os estudos clássicos de Vigotski $(2000,2008)$ e de Jerome Bruner (1997a, 1997b, 2001, 2014), no âmbito da psicologia do desenvolvimento. Em seguida, discutimos as pesquisas de Alison Gopnik (2008) e de Katherine Nelson (2007a, 2007b), antes de apresentar os estudos da neurociência, tendo por referência as obras de Oliver Sacks (2017) e António Damásio (1996, 1999). Em todos esses momentos, buscamos fazer uma interlocução com a pesquisa (auto) biográfica com crianças em educação. Esse caminho reflexivo passará necessariamente por discussões que tratem também de adultos, acompanhando o questionamento de Passeggi (2016b, p. 47): "as noções teórico-conceituais, utilizadas para estudar o mundo adulto, são passiveis do mesmo rendimento para a compreensão do mundo da infância?". Essa diretriz, em nosso caso, decorre também da pouca visibilidade que alguns desses estudos têm na pesquisa autobiográfica, sendo necessário introduzi-los para com eles trabalhar. Essa tentativa se faz na expectativa, ou na aposta, de que poderemos nos deles nos beneficiar direta ou indiretamente.

\section{Em diálogo com uma tradição de estudos}

O mais básico consiste em que a pessoa não somente se desenvolve, mas também constrói a si. (VIGOTSKI, 2000, p. 33)

Construir-se através do narrar-se é um processo incessante e eterno, talvez mais do que nunca. É um processo dialético é um número de um equilibrista. (BRUNER, 2014, p. 95)

São inegáveis as contribuições de Vigotski (2000) e Bruner (2014) para a psicologia do desenvolvimento, entre as quais têm sido bastante contemplados, na literatura, os postulados da mediação semiótica e da internalização das funções psicológicas superiores, do primeiro autor, e a teorização sobre a construção narrativa do self, do segundo. As contribuições desses autores para a pesquisa (auto)biográfica com crianças já foram destacadas por Rocha e Passeggi (2018) e por Passeggi (2018). Desejamos acrescentar à discussão a proposição do drama, na obra de Vigotski, como uma categoria fundamental para a compreensão das funções psicológicas, da memória e da consciência enquanto conceitos-chave para o estudo da criança em desenvolvimento. De Bruner, retomamos a discussão sobre o self e as construções narrativas. Esses autores serão importantes na medida em que trabalhos posteriores, como veremos adiante, retomarão as suas obras.

No início do século XX, Vigotski (1998) observou que nenhuma temática da psicologia de sua época superava os estudos da memória. Suas principais teses sobre a memória caminham na direção do projeto audacioso de revisar e propor alternativas aos impasses dos estudos realizados até então, partindo de ideias mestras. Para o autor, a memória deveria ser estudada em seu desenvolvimento e, nesse sentido, a memorização mediada seria um aspecto crucial na evolução do controle humano dessa função psicológica. Para o autor, um intrincado conjunto de funções estaria articulado - memória, volição, linguagem, consciência - nessa articulação, a memória seria uma das funções psíquicas centrais para o desenvolvimento da criança nos primeiros anos de vida. Nesse sentido, Vigotski se pautará: a) no ato de pensar na descrição de experiência, que, para a criança pequena, significa recordar; b) nas construções mentais na elaboração de conceitos; c) no significado das palavras, que ocupam um lugar de preeminência no processo de 
generalização. Não é de admirar que conclua: "Portanto, a experiência da criança e sua influência imediata, documentada na memória, determina diretamente toda a estrutura do pensamento infantil nas primeiras etapas do desenvolvimento" (VIGOTSKI, 1998, p. 47).

Sem a publicação póstuma do manuscrito de 1929, "Psicologia do homem concreto", a compreensão do pensamento de Vigotski teria ficado bastante limitada. Como se trata de um texto incompleto, convém sublinhar que as novas linhas de pesquisas, sugeridas pelo autor, poderiam ter se desenvolvido se não fosse sua morte prematura aos 37 anos. Convém destacar que o manuscrito é também uma autocrítica de Vigotski. Ele afirmou "Pensa não o pensamento, pensa a pessoa" (2000, p. 33), e logo a seguir: "Minha história do desenvolvimento cultural é a elaboração abstrata da psicologia concreta" (grifo nosso, p. 35). De fato, ao considerar seus estudos, não conseguimos capturar as pessoas em si, mas a construção do pensamento. Um dos conceitos que o autor introduz, então, é o conceito de "drama", relacionando-o à personalidade. Lembremos que Vigotski (1999) foi uma pessoa apaixonada pela dramaturgia e escreveu uma tese sobre Hamlet de Shakespeare. O drama como categoria de trabalho recupera a dinamicidade interna e a construção psicológica do indivíduo, ou da pessoalidade de um modo mais amplo. Em suas palavras: "O drama realmente está repleto de luta interna impossivel nos sistemas orgânicos: a dinâmica da personalidade é o drama" (VIGOSTSKI, 2000, p. 35). Como destacado na epígrafe, a construção da pessoa não é um mero reflexo do meio externo, mas é também a produção de um si mesmo.

A relação entre a linguagem e o pensamento é a mais reconhecida em toda a sua obra. Para Vigotski (2008, p. 132), “A palavra é um

2 Esse título foi dado por A. A. Puzirei. O artigo foi publicado no Brasil pela revista Educação \& Socidade, número especial, n. 71, no ano 2000. microcosmo da consciência humana". Ela resguardaria o pensamento vivo dos indivíduos, ao generalizar, ao particularizar, ao ser campo da ação do ser humano no mundo. Foi Luria (1987, 1992) quem deu prosseguimento aos trabalhos de Vigotski sobre o papel da linguagem e da consciência, sobretudo, avançando para as pesquisas na neuropsicologia. Na contemporaneidade, o neurologista Oliver Sacks (2020) reconheceu, em sua trajetória acadêmica, a importância dos trabalhos de Luria do ponto de vista da neuropsicologia e do seu estilo de escrita narrativo. No Brasil, os conceitos de drama e de subjetividade foram abordados por Fontana (2000), que lançando mão da obra de Bakthin, os situa num quadro mais amplo, dando prosseguimento a obra de Vigotski. Essa pesquisadora ressalta que a consciência do si mesmo se configura através dos outros.

Somente em relação a outro indivíduo tornamonos capazes de perceber nossas características, de delinear nossas peculiaridades pessoais e nossas peculiaridades como profissionais, de diferenciar nossos interesses das metas alheias e de formular julgamentos sobre nós próprios e sobre o nosso fazer. (FONTANA, 2000, p. 62)

Esses autores pós-vigotskianos, que desenvolveram suas pesquisas no quadro das práticas discursivas e da neuropsicologia, como veremos adiante, deram visibilidade a elementos não explorados plenamente nas pesquisas de Vigotski, sobretudo, quanto ao self, à consciência e à identidade.

Quando se trata da construção do self, Jerome Bruner é um autor fundamental ${ }^{3}$, que, reconhece, em muitos momentos, a influência de Vigotski em sua obra. Para Bruner (1997b, p. 136), a narrativa veio a ocupar progressivamente um lugar central na discussão sobre o self. Isso não foi realizado sem certa hesitação

3 Os trabalhos que serão referenciados estão de acordo com as publicações em língua portuguesa, sem necessariamente retratar a cronologia das obras originais na língua inglesa. 
e postergação: “Eu sempre tentei evitar conceitos como Self, e quando fui prensado contra a parede, pulei para fora falando sobre 'rotinas de execução' e circuitos recursivos e estratégias de reparos de enunciados". Anos depois, ao discutir os preceitos fundamentais do desenvolvimento humano, Bruner (2001) destaca o self como elemento chave desse desenvolvimento. $\mathrm{O}$ autor relaciona a agência, as habilidades, o know-how e a avaliação que se faz de si mesmo no mundo ao desenvolvimento da autoestima.

Em Realidade mental, mundos possiveis, Bruner (1997b) reflete sobre o self transacional, esclarecendo a importância das transações para a constituição do eu. Revisita criticamente conceitos hegemônicos como o de egocentrismo infantil, pautando-se em pesquisas sobre a teoria da mente e da linguagem. 0 autor advoga que não há possibilidade de um self isolado e conclui afirmando: "é concebível que nossa sensibilidade à narrativa constitua a principal ligação entre nosso próprio sentido do self e nosso sentido de outros no mundo social a nossa volta" (BRUNER, 1997b, p. 74). Em Atos de Significação (1997a), Bruner aprofunda questões discutidas por ele anteriormente, esclarecendo as bases de sua proposta de uma psicologia popular que estaria

[...] embasada não apenas no que as pessoas fazem, mas no que elas dizem que fazem e no que elas dizem que as fez fazer o que elas fizeram. Ela também está interessada no que as pessoas dizem que os outros fizeram e porquê. $\mathrm{E}$, acima de tudo, ela está interessada em como as pessoas dizem que seus mundos são [...]. (BRUNER, 1997a, p. 25)

Do parágrafo acima, podemos pinçar a importância da narrativa para a constituição do si mesmo, dos outros e do mundo. Esse si mesmo está sempre se justificando, apontando para o futuro, estabelecendo compromissos e estilo de vida. Esse conjunto de ideias fizeram com que Gertz (2001) o elogiasse por sua extensiva e inovadora obra na psicologia, sublinhando sua aproximação com a antropologia e destacando que poderia ser denominada de uma postura radical ou mesmo subversiva. Saliente-se que, para Bruner, o si mesmo não é um ente monolítico, pois se estende inclusive para coisas, para as posses e para outras pessoas. Um si mesmo estendido, segundo Willian James. De tal modo que, em algum momento, um deles corresponderá a um now self, a um eu atual. Bruner também lança mão de um artigo de Markus e Nurius (1986) que trata de selves possiveis. Vale lembrar a explicação dos autores (1986, p. 954, tradução nossa): “Os eus [selves] possiveis representam ideias individuais do que eles podem se tornar, do que eles gostariam de se tornar e do que eles têm medo de se tornar, e, em acréscimo, provê uma relação conceitual entre a cognição e a motivação"4.

Em um dos seus últimos livros, Bruner (2014) retomará e ampliará a compreensão narrativa do self em comparação com a literatura autobiográfica e a ficção. Contudo, a relação entre compromisso e autonomia é um paradoxo que coloca o self sempre diante da atitude de um verdadeiro equilibrista, como sinaliza a epígrafe acima. As possibilidades também se estreitam não sendo, portanto, como a liberdade de romancistas.

Segundo Bruner (1997a, 1997b, 2014), o self é uma construção narrativa entre tantas outras. Contudo, essa dimensão aberta não é um horizonte sem fim, ela depende de vários elementos distintos: a) do capital biográfico acumulado; b) da versatilidade de se compreender como um ente-linguagem; e c) dos horizontes dos possiveis, nos campos sociais em que se situam os agentes. Essas dependências não

4 "Possible selves represent 'individuals' ideas of what they might become, what they would like to become, and what they are afraid of becoming, and thus provide a conceptual link between cognition and motivation". 
podem ser concebidas de um modo reducionista como se cada elemento ou todos viabilizassem ou impedissem de modo categórico e mecânico essa construção. 0 capital biográfico é uma fonte básica, que permite a experiência do si mesmo na temporalidade. Ainda que esse capital seja mínimo, cada pessoa pode lançar mão dele como uma alternativa de si. A consciência de um ente-linguagem produziu obras tão ricas na literatura que possibilitaram nos entrever por meio de selves alternativos, mas essa relação não é automática. O horizonte dos possiveis, mesmo restritos, é o que nos afasta de nos tornarmos autômatos ou marionetes na sociedade. Há um entrecruzamento de nossas histórias com as histórias dos outros na perspectiva em que o(s) outro(s) for$\mathrm{ja}(\mathrm{m})$ e possibilita $(\mathrm{m})$ o olhar recair sobre o si mesmo, sobretudo, por ser mediador de suas próprias memórias na infância e para além dela, na perspectiva de que o(s) outros(s) são exemplos de selves alternativos. Nesse sentido, são lições possíveis de outras formas de se olhar.

O caráter do self como uma ficção, discutido por Bruner (2014) pode ser observado em vários textos e seminários apresentados nos Congressos Internacionais de Pesquisa (Auto) biográfica (CIPA), desde a sua primeira edição, em 2004. De um ponto de vista da experiência do sujeito, é sempre possível nos enredar em sentidos cristalizados, pouco oxigenados, inclusive na infância. A dimensão formativa nas pesquisas (auto)biográficas é um meio para suscitar o desenvolvimento pessoal e grupal, no processo de ressignificação. A reflexividade autobiográfica pode ser um caminho para a mudança, para a (re)afirmação de compromissos passados ou estabelecimento de novos. Algumas linhas da pesquisa (auto)biográfica se direcionam para o papel que exerce um mediador na condução desse processo de reconstrução identitária como na perspectiva do
GEDOMGE ${ }^{5}$ da Universidade de São Paulo (USP) ao postular a produção de uma contramemória profissional, ou do GRIFARS $^{6}$ da Universidade Federal do Rio Grande do Norte (UFRN), ao investir na articulação entre a tríplice mimese ricoeuriana - pré-figuração, configuração e refiguração - com as figuras antropológicas do formador e da pessoa em formação, nos processos de escrita de si (PASSEGGI, 2008). Esses estudos, mais voltados para o adulto, vêm se desenvolvendo, nesta última década, na pesquisa com crianças, enquanto uma linha promissora da pesquisa em educação para a qual o GRIFARS tem tido particularmente um papel crucial.

A pesquisa (auto)biográfica com crianças tem utilizado como procedimento de recolha das fontes contos, rodas de conversas, entrevistas, desenhos, em síntese, a ludicidade. Araújo e Azevedo (2018, p. 96) puseram em relevo o conto como um mediador da relação com o mundo, no ritual iniciático da criança, fazendo-se através de mundo fictício, ajudando-os também "[...] no conhecimento de códigos simbólicos e axiológicos de mundo empírico e histórico-factual". Penã e Cruz (2018) e Goldberg (2018) exploraram os relatos biográficos a partir de desenhos. Um conjunto de trabalhos publicados sobre crianças hospitalizadas do GRIFARS revisita por meio de rodas de conversas as narrativas de crianças na relação escola-hospital (cf. PASSEGGI et al., 2018). Nesse sentido, Rodrigues e Passeggi (2018), ao analisarem as narrativas de crianças hospitalizadas com doenças crônicas, ressaltam que a escola no hospital figuraria como uma continuidade da vida ativa. As narrativas para as crianças propiciam não apenas a compreensão de representações das instituições, mas emergem também como modos de se compreender.

5 Grupo de Estudos Docência Memória e Gênero (cf. CATANI, BUENO, SOUSA, SOUZA, 1997)

6 Grupo de Pesquisa Formação, Auto.Biografia, Representações e Subjetividades. 
O desenvolvimento da consciência de si, do self e da memória, no entanto, faz parte de um longo processo que se desenvolve durante a infância, sendo crucial considerar pesquisas atuais da psicologia que focalizaram essas relações. É o que trataremos no tópico a seguir.

\section{Estudos contemporâneos do desenvolvimento infantil: a contribuição de Gopnik e Nelson}

A compreensão de um sentido de self se desenvolve desde a infância. O si mesmo, na linha do tempo, é uma tarefa complexa do ponto de vista do desenvolvimento humano. Alison Gopnik $(2009,2010)$ e Katherine Nelson (2007a, 2007b) contribuíram significativamente nesses últimos anos, para esse entendimento. Gopnik (2009), em The Philosophical Baby, fez uma ampla revisão de várias capacidades da criança na infância, entre as quais nos interessam a memória, o self e a linguagem. Para essa autora, a memória é mais complexa de que um mero repositório de conteúdos, imagens, lembranças, relacionando-se com o próprio eu (self). Gopnik (2009) relata o caso de H. M., um paciente que teve seu hipocampo destruído em uma cirurgia, malsucedida, para combater a epilepsia. Como resultado, sua memória autobiográfica e sua personalidade sofreram danos irrecuperáveis, embora pudesse aprender fatos novos, a cada encontro com o médico, ele tinha que ser a ele reapresentado. Mesmo quando se deparava, por exemplo, com a sua própria face no espelho, ela the era irreconhecivel.

O self articula dinamicamente o passado, o presente e o futuro. Na infância, o futuro como possibilidade do self se torna possivel, paralelamente, ao desenvolvimento das funções executivas do cérebro, quando o córtex pré-frontal mais se desenvolve. De acordo com Gopnik (2009), posição 2148), as crianças menores não possuem uma memória que thes permitam se situar numa linha do tempo, não tendo, portanto, um '“autobiógrafo interno', um self que possa relacionar os seus estados mentais passados e presentes".

Para a autora, por muito tempo os psicólogos defenderam que os bebês não tinham memórias episódicas, mas, atualmente, tem se evidenciado que eles têm memórias de eventos particulares. Em experimentos controlados, os bebês repetiram a mesma ação dos pesquisadores, que mexiam uma caixa com a testa, um mês depois, quando se depararam com a mesma caixa utilizada no experimento. Crianças muito pequenas têm memórias, que são continuidade das memórias do que os adultos the disseram. As recordações de uma criança por volta de três anos de idade são possiveis mediante uma ajuda externa para ativá-las. Segundo a autora, é por volta de cinco anos de idade que a criança começa a criar narrativas originais sobre os acontecimentos de sua vida, inclusive narrar a sua experiência de aprendizagem. Assim, em crianças menores, a memória se apresenta a partir do aporte externo do outro, que é fundamental para a recordação e o conteúdo das lembranças. As crianças maiores compreendem que se trata de suas próprias memórias, que se diferenciam dos outros, referidos a um passado com pensamentos e sentimentos vinculados.

A memória autobiográfica pode eventualmente conter elementos completamente falsos de experiências que nunca ocorreram de fato, ou mesmo ser inexata em vários pontos, sobretudo quando nos deparamos com situações traumáticas, o que pode também ocorrer na vida adulta. É possível inclusive induzir memórias falsas, por meio de experimentos (GOPNIK, 2009).

Katherine Nelson (2007a, 2007b) é provavelmente uma das autoras mais proeminentes na discussão sobre memória, consciência e 
self no desenvolvimento infantil. Essa autora apresentou um quadro teórico bem articulado do desenvolvimento, partindo de uma abordagem ampla de pesquisa que, ao longo de vários anos, vinculou abordagens metodológicas múltiplas, incluindo pesquisas no ambiente natural das crianças, abordagens comparativas, testes de hipóteses, experimentos em laboratório, de modo a recuperar ambientes e situações naturais. Nelson (2007b) trabalha com um modelo de sistema dinâmico, por isso seria reducionista e limitador interpretar seus estudos em termos do debate Piaget-Vigotski. Contudo, na sua perspectiva, um dos pontos chaves para o entendimento do desenvolvimento infantil é a ênfase da pesquisa em como crianças atribuem sentido a sua experiência no mundo e não em como elas interpretam o significado do mundo, como quer a epistemologia genética.

As fases por ela propostas de desenvolvimento na infância podem lembrar os modelos etapistas. Contudo, Nelson (2007b) faz várias ressalvas quanto aos seus esboços interpretativos, destacamos entre outros: a) a coerência entre as partes integrantes em um sistema; $b$ ) a dinamicidade referente aos ajustes em novas condições contextuais; c) o movimento do sistema em termos de contínua organização e não de equilíbrios; d) a complexidade mental em expansão e em transação experiencial; e) a não uniformidade nas etapas descritas que podem decorrer de características pessoais, experiências sociais e culturais. Ao considerar todas essas observações, Nelson (2007a; 2007b) elabora uma sequenciação ${ }^{7}$ de etapas que vai de zero a seis anos de idade no tocante à construção do self, considerado com um modelo de desenvolvimento sociocultural. Em sintese, destacamos desse modelo:

a) Self Físico: recém-nascido - caracterizado pelo apego emocional e pela interação di-

7 Cf. as idades propostas se superpõem. ferenciadora no mundo, mas não há uma consciência do self por si mesmo;

b) Self Social: de 6 a 12 meses - caracterizado pelo compartilhamento social, contrastes relacionais pela observação dirigida a pessoas, rotinas, objetos e palavras;

c) Self Cognitivo: de 18 a 24 meses - caracterizado pela perspectiva eu-você, do estágio do reconhecimento da imagem no espelho, no uso de pronomes pessoais ou de identificação pessoal do próprio nome, capacidade inicial de se colocar na perspectiva do outro. Atenção voltada para sentimentos de embaraço, vergonha, inibição;

d) Self Representacional: de 2 a 4 anos - caracterizado pela memória episódica e o início da narrativa de experiências do passado. Sentimento de continuidade do ser e compreensão da minha mente/sua mente;

e) Self Narrativo: de 3 a 6 anos - caracterizado por uma visão de si como um todo integrado e estável, que se diferencia dos outros por sua história, por suas experiências de passado e futuro;

f) Self Cultural: de 5 a 7 anos - caracterizado por uma compreensão do lugar do self em um conjunto amplo, em uma cultura, na perspectiva de nossa história no mundo, em uma compreensão mais ampla das regras culturais, das instituições, da cultura.

Essas fases denominadas por Nelson (2007a) de Self Físico, Social, Cognitivo, Representacional, Narrativo e Cultural devem ser entendidas em termos de ênfase, como sínteses amplas de caracterização, e não em termos de exclusividade, o que poderia induzir a uma compreensão errônea e limitada, se tomadas de modo isolado. Sabemos, por exemplo, que a cognição se desenvolve desde tenra infância, havendo inúmeras relações com a motricidade, com os reflexos biológicos, com a afetividade. Também sabemos do papel fundante do outro - da sociedade - na construção das funções psicológicas e na construção do próprio 
eu. Nelson e outros autores (1989), inclusive, consideraram o valor das narrativas na mais tenra idade, no livro Narratives from the Crib ${ }^{8}$, o que não implica dizer que a descrição de uma construção articulada e qualitativamente superior, tal como se desenha a partir dos três anos de idade (Self Narrativo). Antes disso, temos o papel desempenhado pelo monólogo, em etapas mais iniciais, como uma representação da experiência de vida-real. Portanto, as etapas propostas por Nelson (2007a, 2007b), descritas anteriormente, devem ser entendidas pelo viés de uma construção integrada. Como tal, a nomeação de algumas características em detrimento de outras pode fazer sugerir uma limitação teórica, mas isso decorre, de fato, de uma limitação da própria linguagem, em sua tentativa de definir a realidade complexa, de um modo didático.

Por fim, vale salientar que Nelson e Fivush (2019) consideraram o desenvolvimento da memória sob o prisma do self e da narrativa. Para as autoras, há um desenvolvimento que caminha inicialmente da memória episódica para a memória autobiográfica, daí para a construção da narrativa autobiográfica para, finalmente, emergir a consciência autobiográfica. Esses resultados nos pareceram fundamentais, lançando luz para as pesquisas com crianças em nosso meio. Esse é um processo que percorre um desenvolvimento complexo. Segundo as autoras, esse processo decorre de aprendizagens cotidianas, em interações sociais mediadas linguisticamente, de tal modo "a linguagem é um mecanismo sem o qual essa forma particular de consciência autobiográfica humana não se desenvolve" (2019, p. 72, tradução nossa). Uma explicitação ampla da abordagem traçada fugiria ao escopo deste artigo, ainda que se faça ainda necessária em momento posterior, sobretudo, por não ter tido ainda desdobramentos na pesquisa brasileira.

8 "Narrativas a partir do berço" (tradução nossa).

\section{Estudos da neurociência}

Consciousness is the biggest mystery9. (CHALMERS, 1996, p. xi).

A discussão sobre a consciência ganhou vitalidade na neurociência na década de 1990, conhecida como a década do cérebro. Em 2003, Crick e Koch propuseram um quadro interpretativo de sintese de seus trabalhos anteriores, considerando central o ponto de vista perceptual para a consciência, sendo pioneiros nesses estudos de base neural. Para Sacks (2017), as hipóteses desses pesquisadores como de autores clássicos da psicologia e filosofia devem ser levadas em consideração no estudo do fluxo da consciência. Sacks (2017) tem por base as experiências clínicas de pacientes com graves transtornos neurológicos, enxaquecas e usuários de alucinógenos. Alguns desses podem apresentar problemas nesse fluxo, ao perceber imagens paralisadas por minutos ou horas seguidas, tendo uma correlação direta com essa "parada" no fluxo do pensamento e da ação. Seguindo a tradição de W. James, Sacks (2017) observa que esses casos não são apenas um fenômeno neurológico, mas interpretativo e pessoal, relacionados à linguagem e a um conjunto de percepções, memórias, associações, sentimentos, significados. A consciência é um fenômeno humano que se consubstancia na temporalidade e nas experiências singulares dos sujeitos.

Por que, dentre milhares de outras percepções possiveis, são essas que capto? Por trás delas há reflexões, memórias, associações. Pois a consciência é sempre ativa e seletiva, carregada de sentimentos e significados unicamente nossos, que fundamentam nossas escolhas e permeiam nossas percepções. Por isso, não é apenas a Sétima Avenida que vejo, mas a minha Sétima Avenida, marcada pela minha individualidade e identidade. (SACKS, 2017, posição 2052, edição kindle)

9 "A Consciência é o maior de todos os mistérios" (tradução nossa). 
Na linha de Sacks (2017), a neurociência procura reabilitar a dimensão da pessoalidade perdida nos estudos voltados para explicar as funções neurológicas. Segundo o referido neurologista, a experiência da leitura que fez do caso do Mnemonista de Luria (2006) permitiuthe acender mais ainda o seu amor por narrativas. Essa linha de continuidade - Vigotski -Luria-Sacks -contribuiu para desenvolver estudos que retificariam o trajeto a favor de uma "psicologia concreta" postulada por Vigotski. A estreita relação entre consciência, memória e construção da subjetividade, entendida como o eu (self) não pode passar aqui despercebida.

A questão da individualidade na construção da percepção do mundo, colocada por Sacks (2017), na qual se entrecruzam memórias, experiências no mundo, sentimentos e pensamentos são bem conhecidas na pesquisa (auto)biográfica. Essas percepções também são produtos de diálogos incessantes com os outros, desde aqueles com os quais nos identificamos até aqueles aos quais nos opomos. Segundo Delory-Momberger (2012), a pesquisa biográfica tem procurado conceber os indivíduos para além do que se denominou "sociologia do indivíduo". Essa busca procede por uma redefinição teórico-metodológica, uma vez que as ciências humanas e sociais, até os anos 1980, jogaram aspectos da pessoalidade na vala comum do resíduo da subjetividade, como elementos indignos da ciência.

António Damásio é outro autor fundamental na neurociência para as discussões em tela. Em O erro de Descartes: emoção, razão e o cérebro humano (1996), o autor introduz a problemática da consciência e do eu, aventando a hipótese de que a base neural do eu seria fundamental para "esclarecer o processo de subjetividade, característica-chave da consciência" (ib., p. 267). Posteriormente, na obra O mistério da consciência: do corpo e das emoções ao conhecimento de si (1999), o autor ampliará suas hi- póteses e introduzirá uma discussão pormenorizada do self, considerando o proto-self, o self neural e o self autobiográfico. Esse livro traz hipóteses e dados provenientes da clínica neurológica e de estudos neuropsicológicos. Os achados da clínica médica, se conduzidos com o olhar científico, são cruciais para o progresso do diagnóstico e do tratamento. Para Damásio (1999), esses dados se tornam campo de especulações logicamente encadeadas e promissoras por seu caráter inovador. Delas, emergem o tema fundamental da obra da consciência e suas bases neurológicas, que se ampliou ou se tornou mais complexo ao ser vinculado ao self e que destoam de ideias comumente aceitas nas ciências humanas, como, por exemplo, o lugar da linguagem na construção do self.

Para o autor (1999), o self central (ou transitório) e o self autobiográfico necessitam de uma estabilidade, uma invariância estrutural, uma continuidade de referência. Existe um precursor: o proto-self, relativo ao corpo com seus sistemas de "termostatos" e de representações neurais integradas ao meio interno, associados à pele, às estruturas muscoesqueléticas e às vísceras, funcionando como um sistema integrador da estabilidade e permitindo um "retrato do estado vivo". Damásio (1999, posição 2828) define o proto-self, ou self neural, como "um conjunto coerente de padrões neurais que mapeiam, a cada momento, o estado da estrutura física do organismo nas suas numerosas dimensões". Ainda segundo Damásio (ib.), não estamos conscientes do proto-self e a linguagem não é parte de sua estrutura, uma vez que não dispõe de capacidade de reflexão, de conhecimento ou de interpretação. o proto-self operaria de um modo narrativo imagético.

O self necessita de um corpo, enquanto raiz da singularidade. Nesse sentido, pode-se considerar que o proto-self é de extrema importância. Segundo Damásio (1999, posição 2951), “Não fosse esse magnífico mecanismo, 
é possivel que nunca tivéssemos desenvolvido um self autobiográfico". Algumas estruturas neurológicas são responsáveis pelo proto-self: os núcleos do tronco cerebral, o hipotálamo, o córtex insular, os córtices denominados "S2" e os parietais mediais. Outras não têm relação com proto-self, como os córtices sensoriais iniciais, os inferiores temporais, o hipocampo, os córtices relacionados ao hipocampo, os pré-frontais e o cerebelo. Uma das pacientes de Damásio (1999) não conseguia reconhecer rostos dos familiares e de amigos muito próximos, nem mesmo o seu próprio. Colocada frente a um espelho, só se reconhecia, por dedução. Como fora levada diante do espelho, então pensava: "deve ser eu, pois estou aqui". Ela podia reconhecer sua voz gravada, mas não sua própria face. Em um experimento controlado com fotos, fez deduções de que a foto de qualquer pessoa com um dente um pouco mais escuro na arcada superior, ou semelhante, poderia ser a da sua filha, pois lembrava dessa sua característica. Outro caso ilustrativo é o de um cantor de ópera que, por causa de um derrame, perdeu a capacidade de reconhecer vozes, inclusive as de seus colegas de trabalho. Contudo, apesar de sérias limitações, eles podiam manter a consciência central.

Para Damásio, quando um objeto é realçado pela mente, iluminado pelo ato de conhecer por meio da consciência, tem-se então o self central, pois o indivíduo tem consciência que sente, ouve, toca. Esse self se origina quando "um objeto modifica o proto-self" (1999, posição 3182). E o que seria um self autobiográfico na concepção do autor? O self autobiográfico

[...] baseia-se na memória autobiográfica, que é constituída por memórias implícitas de múltiplos exemplos de experiência individual do passado e do futuro antevisto. Os aspectos invariáveis da biografia do indivíduo formam a base da memória autobiográfica. (DAMÁSIO, 1999, posição 3175)
É importante reconhecer que o self autobiográfico não se movimenta apenas para o passado, mas ele também transita no presente e no futuro, antecipando, tendo expectativas, planejando. A temporalidade é um dos pontos nevrálgicos da pesquisa (auto)biográfica.

A discussão sobre o proto-self, proposta por Damásio (op. cit.), causa estranhamento, sobretudo ao considerarmos que haveria nessa perspectiva uma narrativa sem palavras. Insistimos que, segundo o autor, não temos consciência do proto-self. E como mencionamos anteriormente, a linguagem não é parte de sua estrutura, por essa razão, seria desprovido da capacidade de reflexão, de conhecimento e de interpretação. 0 proto-self, em sua proposição, operaria de um modo narrativo imagético. Nessa linha de raciocínio, Crick; Koch (2003) e Sacks (2017) assinalaram a importância das imagens na configuração da consciência. Damásio (1999, posição 2951) vai além: “Não fosse esse magnífico mecanismo, é possivel que nunca tivéssemos desenvolvido um self autobiográfico". o que se pode sumariar é que o self autobiográfico é uma estrutura complexa do ponto de vista psicológico e neurológico, sendo necessário, na hipótese de Damásio (1999), o desenvolvimento do cérebro e do proto-self, que the serviria de base.

\section{Considerações finais provisórias: complexificação do olhar}

[...] o sujeito em diferentes fases da vida, apropria-se de instrumentos semióticos (a linguagem natural, o grafismo, o desenho, os gestos etc.) para configurar suas experiências em narrativas que até então não existiam, mas uma vez enunciadas, elas adquirem vida e pelas quais o narrador torna-se responsável diante de si e dos outros [...]. (PASSEGGI, 2016b, p. 49)

As pesquisas e as hipóteses da neurociência, arroladas neste artigo, corroboram uma visão integradora e evolutiva do desenvolvimen- 
to humano, tornando-se um aporte valioso na superação de abordagens dicotômicas e mecanicistas da ciência, sobretudo em medicina. Ainda que a pesquisa (auto)biográfica venha desenvolvendo pesquisas na interface entre educação e saúde e contribuindo para o que se denominou "medicina narrativa", é notória a importância dos casos clínicos e as hipóteses construídas pelas neurociências para outras percepções do lugar que a memória ocupa no desenvolvimento humano como um todo, notadamente, sobre a consciência no desenvolvimento do self autobiográfico, que incidiria sobre a própria sobrevivência do indivíduo. A memória, enquanto função psicológica, certamente não seria apenas um repositório de lembranças, ela é necessária para que o sujeito, no ato de narrar, retorne ao passado, se veja no presente e projete no futuro - breve ou longínquo -, movimentos com os quais elabora o auto(re)conhecimento e a autocompreensão.

A memória humana se apresenta em várias nuanças e percorre um desenvolvimento que progressivamente a torna mais complexa, juntamente com o self e a consciência. A retomada dos estudos, aqui traçados, em linhas gerais, pretendeu evidenciar múltiplas relações e interdependências nesse quadro. As pesquisas sobre o desenvolvimento da memória em um aporte mais desenvolvimental possibilitam, particularmente, ampliar a compreensão da criança de um modo mais rico e integrado. Tanto Nelson (2007a, 2007b) quanto Gopnik (2009) evidenciam que a memória se desenvolve de modo progressivo, possibilitando um entendimento mais amplo do si mesmo, dos outros e do mundo circundante. A consciência autobiográfica, na criança, emerge como o resultado uma história que vai incorporando e se diferenciando do outro no seu próprio mundo. Isso também tem sido sinalizado nos estudos realizados no âmbito da pesquisa (auto) biográfica com crianças. Nosso propósito, foi trazer novos aportes da psicologia do desenvolvimento, de modo a contribuir para ampliar o quadro teórico, sobretudo sobre a constituição da subjetividade na criança com base nos estudos de Katherine Nelson (2007a, 2007b) sobre as distintas fases do self na infância.

Passeggi (2016a) vem discutindo sobre as três dimensões da subjetividade, apresentando o entrelaçamento entre o sujeito da experiência - empírico, de carne e osso -, o sujeito epistêmico - cognitivo, racional - e o sujeito autobiográfico - feito de linguagem. Ao considerar as narrativas de crianças, é importante lembrar que a narração não se constitui da mesma forma, quando elaborada por um jovem ou pelo adulto. Em sua perspectiva, é o sujeito autobiográfico, que no ato de narrar, associa razão e emoção, e que mediante a linguagem - verbal e não verbal - dá sentido, sempre provisório, ao que acontece no mundo exterior e ao que the acontece no mundo interior. Esse entendimento é cotejado pela compreensão de que a criança, no seu processo de desenvolvimento, é igualmente dotada de reflexividade autobiográfica, cabendo ao pesquisador saber interpretar o conhecimento subjacentes ao seu modo de se perceber no mundo. As pesquisas aqui esboçadas podem ser um rico contributo para futuras aproximações nesse sentido.

A pesquisa (auto)biográfica é uma das vertentes da pesquisa qualitativa em educação que se centra na compreensão da criança concreta e como tal se aproxima da diretriz proposta por Vigotski (2000) de uma psicologia do homem concreto, a qual toma como categoria o drama vivido na cotidianidade, cuja expressão se faz com base na narrativa. Ao longo das últimas décadas, essa perspectiva vem oferecendo uma rica contribuição ao entendimento da constituição da singularidade humana. Por fim, os aportes atuais da psicologia do desenvolvimento também têm muito a contribuir 
tendo em vista a especificidade do saber que se constitui mediante $o$ ato de narrar a experiência vivida, fundada na temporalidade do humano.

\section{Referências}

ARAÚJO, Alberto Felipo, AZEVEDO, Fernanda. Narrativa e infância. A importância dos contos no ritual iniciático das crianças. In: PASSEGGI, Maria da Conceição; DEMARTINI, Zélia de Brito Fabri; NOVAES, Adelina de Oliveira (Org). Infâncias, juventudes, universos (auto)biográficos e narrativas. Curitiba: CRV, 2018. p. 95-111.

BAUMAN, Zygmunt.; RAUD, Rein. A individualidade em um tempo de incertezas. Rio de Janeiro: Zahar, 2018.

BRUNER, Jerome. Atos de significação. Porto Alegre: Artes Médicas, 1997a.

BRUNER, Jerome. A cultura da educação. Porto Alegre: Artmed, 2001.

BRUNER, Jerome. Fabricando histórias: direito, literatura e vida. São Paulo: Letra e Voz, 2014.

BRUNER, Jerome. Realidade mental, mundos possiveis. Porto Alegre: Artes Médicas, 1997b.

CATANI, Denice Barbara; BUENO, Belmira Oliveira; SOUSA, Cynthia Pereira; SOUZA, Maria Cecília C. C. (Orgs.). Docência, memória e gênero: estudos sobre a formação. São Paulo: Escrituras, 1997.

DAMÁSIO, António. 0 erro de Descartes. São Paulo: Companhia das Letras, 1996.

DAMÁSIO, António. $\mathbf{0}$ mistério da consciência: do corpo, das emoções, do conhecimento de si. São Paulo: Companhia das Letras, 1999.

DEMARTINI, Zeila de Brito Fabri. Infância, pesquisa e relatos orais. In: FARIA, Ana Lúcia Goulart de.; DEMARTINI, Zelia de Brito Fabri.; PRADO, Patrícia Dias. (Org.). Por uma cultura da infância: metodologias de pesquisas com crianças. 3 ed. Campinas: Autores Associados, 2009. p. 1-17.

FIORI, Nicole. As neurociências cognitivas. Petrópolis: Vozes, 2008.
FONTANA, Roseli A. Cação. Como nos tornamos professoras? Belo Horizonte: Autêntica, 2000.

FOUCAULT, Michel. A hermenêutica do sujeito. São Paulo: Martins fontes, 2019.

GERTZ, Clifford. Nova luz sobre a antropologia. Rio de Janeiro: Zahar, 2001.

GIDDENS, Antony. Modernidade e identidade. Rio de Janeiro: Zahar, 2002.

GOLDBERG, Luciane Germano. Autobiografismo: a criança em situação de acolhimento institucional. In: PASSEGGI, Maria da Conceição; LANI-BAYLE, Martine; FURLANETTO, Ecleide Cunico; ROCHA, simone Maria da. (Orgs.). Pesquisa (auto)biográfica em educação: infâncias e adolescências em espaços escolares e não escolares. 1ed. Natal: EDUFRN, 2018. p. 375-396.

GOPNIK, Alison. Como os bebês pensam. Scientific American Brasil. São Paulo, n. 99, p. 62-76, 2010. Disponivel em: https://www.livrariadafisica.com. $\mathrm{br} /$ detalhe_produto.aspx? $\mathrm{id}=101179 \&$ titulo $=$ Scien tific+American+Brasil+Ed.+n\%C2\%BA+99+-+O+que+os+beb\%c3\%AAs+sabem+e+os+adultos+desconhecem Acesso em: 07 de abr. de 2020.

GOPNIK, Alison. The philosophical baby: what children's minds tells us about truth, love and the meaning of life. Ney York: Farrar, Straus and Giroux, 2009. (Edição do Kindle).

HORDAN, John. A mente desconhecida: porque a ciência não consegue replicar, medicar e explicar o cérebro humano. São Paulo: Companhia das Letras, 2002.

HOUDÉ, Oliver; MELJAK, Claire. 0 espírito piagetiano: homenagem internacional a Jean Piaget. Porto Alegre: Artmed, 2002.

LIRA, André Augusto Diniz. Entre memória e identidades sociais. Interface. Ano 1, n. 2, jul./dez. p. 73-81, 2004. Disponivel em: https://ojs.ccsa.ufrn.br/ index.php/interface/article/view/22 Acesso em: 07 de abr. de 2020.

LURIA, Alexander Romanovich. A Construção da mente. São Paulo: Icone, 1992. 
LURIA, Alexander Romanovich. A mente e a memória. São Paulo: Martins Fontes, 2006.

LURIA, Alexander Romanovich. Pensamento e linguagem: as últimas conferências de Luria. Porto Alegre: Artmed, 1987.

MADRUGA, Juan Antonio Garcia.; MARTINEZ, Francisco Gutierrez Fernandres.; CHAVES, José Oscar Vila. Desenvolvimento da memória. In: CARRETERO, Mário.; CASTORINA, José. (Orgs.) Desenvolvimento Cognitivo e educação: processos do conhecimento e conteúdos específicos. Porto Alegre: Penso, 2014. p. 41-63.

MARKUS, Hazel; NURIUS, Paula. Possible Selves. American Psychologist. 41(9), p. 954-969, 1986. DOI: 10.1037/0003-066X.41.9.954

MARTINS, José de Sousa. Fronteira: a degradação do outro nos confins do mundo. São Paulo: Contexto, 2014.

NELSON, Katherine. Narrative and Self, Myth and Memory: emergence of the cultural self. In: FIVUSH, Robyn, HADEN Catherine A. (Edit.). Autobiographical memory and the construction of a narrative self: developmental and cultural perspectives. Londres: Taylor and Francis. 2007a. (Edição do Kindle).

NELSON, Katherine et. al. (edit.). Narratives from the crib. Cambridge: Harvard University Press, 2006.

NELSON, Katherine. Young minds in social words: experience, meaning, and memory. Cambridge: Harvard University Press, 2007b.

NELSON, Katherine; FIVUSH, Robyn. The development of autobiographical memory, autobiographical narratives, and autobiographical consciousness. Psychological Reports. n. 123, v. 1, p. 71-96. 2019. Disponivel: https://pubmed.ncbi.nlm.nih. gov/31142189/. Acesso em: 07 abr. 2020.

PASSEGGI, Maria da Conceição. Mediação biográfica: figuras antropológicas do narrador e do formador. In: PASSEGGI, Maria da Conceição. BARBOSA, Tatyana Mabel Barbosa. Memórias, memoriais: pesquisa e formação docente. Natal: EDUFRN; São Paulo: Paulus, 2008. p. 43-59.

PASSEGGI, Maria da Conceição. Narrativas da expe- riência na pesquisa formação: do sujeito epistêmico ao sujeito biográfico. Roteiro, Joaçaba, n. 1, p. 6786, jan./abr. 2016a. Disponivel em: https://dialnet. unirioja.es/descarga/articulo/6195624.pdf. Acesso em: 10 fev. 2018.

PASSEGGI, Maria da Conceição. O sujeito autobiográfico: noções terminológicas para a pesquisa (auto)biográfica com crianças. In: PASSEGGI, Maria da Conceição; FURLANETTO, Ecleide Cunico; PALMA, Rute Cristina Domingos da (Orgs.) Pesquisa (auto) biográfica, infâncias, escola e diálogos intergeracionais. Curitiba: CRV, 2016b. p. 47-66.

PASSEGGI, Maria da Conceição. Nada para criança, sem a criança. In PASSEGGI, Maria da Conceição; LANI-BAYLE, Martine; FURLANETTO, Ecleide Cunico; ROCHA, Simone Maria da. (Orgs.). Pesquisa autobiográfica em educação: infâncias e adolescências em espaços escolares e não-escolares. Natal, RN: EDUFRN, 2018. p. 103-121.

PASSEGGI, Maria da Conceição; LANI-BAYLE, Martine; FURLANETTO, Ecleide Cunico; ROCHA, Simone Maria da. (Orgs.). Pesquisa (auto)biográfica em educação: infâncias e adolescências em espaços escolares e não escolares. 1ed. Natal: EDUFRN, 2018.

POLLAK, Michel. Memória e identidade social. Estudos Históricos, Rio de Janeiro, v. 5, n. 10, p. 200212, 1992. Disponivel em: http://www.pgedf.ufpr.br/ memoria\%20e\%20identidadesocial\%20A\%20capraro\%202.pdf. Acesso em 25 de jun. de 2018.

POLLAK, Michel. Memória, esquecimento e silêncio. Estudos Históricos, Rio de Janeiro, v. 2, n. 3, p. 3-15, 1989. Disponivel em: http://www.pgedf.ufpr.br/memoria\%20e\%20identidadesocial\%20A\%20capraro\%202.pdf. Acesso em 11 de mar. de 2017.

ROCHA, Simone Maria da.; PASSEGGI, Maria da Conceição. Inclusão pela classe hospitalar: o que nos contam as crianças sobre suas experiências de vida no hospital. In: SOUZA, Elizeu Clementino; PASSEGGI, Maria da Conceição; VICENTINI, Paula Perin. Pesquisa (auto)biográfica: trajetórias de formação e profissionalização. Curitiba: CRV, 2018. p. 107-121.

RODRIGUES, B. B. S; PASSEGGI, Maria da Conceição. Entre Escolas e Hospitais. In: PASSEGGI, Maria da 
Conceição; LANI-BAYLE, Martine; FURLANETTO, Ecleide Cunico; ROCHA, Simone Maria da. (Orgs.). Pesquisa (auto)biográfica em educação: infâncias e adolescências em espaços escolares e não escolares. 1ed. Natal: EDUFRN, 2018. p. 467-488.

ROSE, Nikolas. Inventando nossos selfs: psicologia, poder e subjetividade. Petrópolis: Vozes, 2011.

SÁ, Celso Pereira de. Memória, imaginário e representações sociais. Rio de Janeiro: Museu da República, 2005.

SACKS, Oliver. 0 rio da consciência. São Paulo: Companhia das Letras, 2017.

SACKS, Oliver. Oliver Sacks, em uma conversa sobre Alexander Luria. Disponivel em: https://www.youtube.com/watch?v=II-68VFGTWQ. Acesso em: 27 jun. 2020.

SANTOS, M. S. dos. Sobre a Autonomia das Novas Identidades Coletivas: alguns problemas teóricos. Revista Brasileira de Ciências Sociais, São Paulo, v. 13, n. 38, p. 1-16, São Paulo, out. 1998. Disponível em: https:// www.scielo.br/scielo.php?script=sci_arttext\&pid=S0102-69091998000300010. Acesso em: 7 jun. 2020.

SELIGMAN-SILVA, Márcio. (Org.) História, Memória e Literatura: o testemunho na era das catástrofes. Campinas: Editora da Unicamp, 2003.

SHEIBE, Karl E. Self studies: the psychology of self and identity. London: Praeguer, 1995.

VIGOTSKI, L. S. A tragédia da Hamlet, príncipe da Dinamarca. São Paulo: Martins Fontes, 1999.

VIGOTSKI, L. S. 0 desenvolvimento psicológico na infância. São Paulo: Martins Fontes, 1998.

VIGOTSKI, L. S. Pensamento e linguagem. São Paulo: Martins Fontes, 2008

VIGOTSKI, L. S. Psicologia concreta do homem. Educação \& Sociedade, ano XXI, n. 71, p. 23-44, julho, 2000. (Número Especial Vigotski - O manuscrito de 1929: temas sobre a constituição cultural do homem). Disponivel em: https://www.scielo.br/pdf/ es/v21n71/a02v2171.pdf. Acesso em: 10 ago. 2017.

WALLON, Henri. Do ato ao pensamento: ensaio de psicologia comparada. Petrópolis: Vozes, 2015.

Recebido em: 01/07/2020 Revisado em: 18/08/2020 Aprovado em: 24/08/2020

André Augusto Diniz Lira é doutor em Educação pela Universidade Federal do Rio Grande do Norte (UFRN). Professor do Programa de Pós-graduação em Educação da Universidade Federal de Campina Grande (UFCG). Pesquisador Associado ao Centro Internacional de Estudos em Representações Sociais e Subjetividade - Educação (CIERS-Ed) da Fundação Carlos Chagas (FCC). Líder do grupo de pesquisa Sociedade, Cultura e Educação (GPESCE). Tutor do PET-Pedagogia da UFCG. E-mail: andreaugustoufcg@gmail.com

Renata Carlos de Oliveira Gonçalves é mestra em Educação na Universidade Federal de Campina Grande (UFCG). Integra o Grupo de pesquisa Sociedade, Cultura e Educação (GPESCE). E-mail: renataoliveira.au@gmail.com 